Research Article

\title{
Investigating the Influences of Indentation Hardness and Brittleness of Rock-Like Material on Its Mechanical Crushing Behaviors
}

\author{
Jiuqun Zou, Jihuan Han $(D$, and Weihao Yang \\ State Key Laboratory for Geomechanics and Deep Underground Engineering, China University of Mining and Technology, \\ Xuzhou 221116, Jiangsu Province, China \\ Correspondence should be addressed to Jihuan Han; hanjhcumt@sina.com
}

Received 23 June 2020; Revised 5 August 2020; Accepted 19 August 2020; Published 8 September 2020

Academic Editor: Nhon Nguyen-Thanh

Copyright (c) 2020 Jiuqun Zou et al. This is an open access article distributed under the Creative Commons Attribution License, which permits unrestricted use, distribution, and reproduction in any medium, provided the original work is properly cited.

Indentation hardness and brittleness are the important factors to be considered in the study of rock-like materials' mechanical crushing behaviors. The brittleness of rock-like materials is defined as the ratio of uniaxial compressive strength to tensile strength in this paper. In order to investigate the influences of hardness and brittleness on rock-like materials' crushing behaviors, quartz sand and high strength $\alpha$-hemi-hydrated gypsum were used to prepare rock-like materials with different hardness and brittleness through different mass ratios. The artificial rock-like materials can eliminate the effects of natural rock's weak structure plane on experimental results. The indentation test, Uniaxial compressive test, and Brazilian tensile test were conducted for characterizing the indentation hardness and brittleness of this artificial rock-like materials. The experimental results showed that brittleness increased with the increase of indentation hardness with high correlation coefficient. The confining stress presented a positive impact on the indentation hardness of the rock-like materials. Based on those mechanical properties, the numerical rock models were calculated to study rock crushing behaviors using discrete element method (DEM). A series of rock crushing tests were conducted to investigate the influences of hardness and brittleness of rock-like materials on rock crushing behaviors using a conical pick cutter. The numerical results showed that the normalized specific energy was negatively correlated with indentation hardness index (IHI). The normalized specific energy decreased with the increase of brittleness index (BI) with a high correlation coefficient. This study is beneficial in utilizing IHI and BI to evaluate the mechanical properties, failure patterns, and mechanical crushing efficiency of rock-like materials.

\section{Introduction}

Understanding of rock hardness and brittleness has a crucial importance for practical underground construction engineering. The correlation between hardness and brittleness of rock materials and their mechanical properties and failure patterns has been the focus of research hotspot in related fields. Szwedzicki [1] employed the indentation test for measuring rock hardness and stated that this test could be used for characterization of rocks' mechanical properties. There exists a relationship between the value of the indentation hardness and the uniaxial compressive strength (UCS). Yagiz [2] stated that the indentation hardness could be directly used for measuring rock toughness and brittleness, and the measured index had a close correlation with UCS and density of rocks. Shalabi et al. [3] suggested that there is a good relationship between the engineering properties (such as strength, modulus of elasticity, and Poisson's ratio) of the intact rock and its hardness (Schmidt, shore scleroscope, abrasion, and total hardness). Xuefeng et al. [4] investigated the influences of rock brittleness on rock crushing behaviors and suggested that rock brittleness had a dominant effect on rock failure patterns. Fan et al. [5] investigated the mechanical characterization of shale through instrumented indentation test and stated that the indentation hardness could be used to obtain the elastic modulus, hardness, and brittleness. Therefore, hardness and brittleness can be used as the important indexes to 
characterize the mechanical properties and failure patterns of rock materials.

In addition, many numerical studies had been conducted on the failure of brittle rock materials utilizing discrete element method. Li et al. [6] studied the brittle rock indentation process and rock-tool interactions by particle flow code (PFC). The results revealed that the tensile cracks are resulted from the chipping process and the shear cracks are induced by the crushing force. Li et al. [7] investigated the crack initiation and propagation mechanism in brittle rocks using grain-based finite-discrete element method. The compression testing under different end friction, slenderness, loading rate, and confining stress are systematically performed to investigate the external influences on rock fracturing. It can be seen that the fragmentation patterns of brittle rocks are related to many mechanical properties of rocks and external factors. The DEM has advantages in the numerical investigation of brittle rocks' mechanics fragmentation.

In practical underground constructions, mechanical rock crushing is a continuous, efficient and safe technique exhibiting great superiority in geotechnical engineering [8]. Many researchers [8-10] have investigated rock crushing behaviors through different indentation tests. Specific energy (SE) is always used to evaluate the rock crushing efficiency, which is defined as the amount of work required to break per unit volume of rocks. Yilmaz et al. [11] stated that the hybrid dynamic hardness had the potential to be used as an index rock material property that can be employed in preliminary estimations of specific energy (SE) and cutting force for a wide range of rocks under different operational conditions. Ji et al. [12] investigated the effects of ductilitybrittleness change on rock fragmentation process and its failure mode. As the brittleness of the model increased, the normalized specific energy decreased and the efficiency of the rock crushing increased. Consequently, this paper investigates the correlation between mechanical properties and failure patterns of rock materials and their brittleness as well as indentation hardness based on rock crushing behaviors.

Although using only one mechanical parameter always cannot accurately predict the rock crushing behaviors, a large number of studies have shown that there exists a close correlation between those rock mechanical parameters (such as strength, modulus of elasticity, toughness, Poisson's ratio, and density) and hardness as well as brittleness. Balci et al. [13] tested 23 different rock specimens and investigated the predictability of SE from physical and mechanical properties. The results showed good correlations between SE and rock properties, such as UCS, Brazilian tensile strength (BTS), static and dynamic elastic moduli, and the Schmidt hammer value. Singh [14] observed that the in situ SE strongly depended upon the brittleness, UCS, Protodyakonov strength index, coefficient of internal friction, and the initial critical penetration stress. Therefore, it is worth investigating the influence of rock indentation hardness and brittleness on rock crushing behaviors. Because rock failure process is not visible, the mechanism of influence of hardness and brittleness on rock crushing behaviors remains unclear. Very few studies have investigated the hardness and brittleness of rock materials on their crushing behaviors utilizing pick cutters. Moreover, the IHI and BI indexes can be used to quantitatively characterize rocks' mechanical crushing behaviors.

Indentation test is the most common method to obtain IHI of rock materials. In generally, the IHI is calculated by equation (1) $[1,2]$. Here, $F_{\max }$ is the maximum thrusting force of indenter at the specific penetration, $P$ is the penetration depth. Rock brittleness is defined as the ability of rocks to deform continuously without permanent deformations along with the application of stress surpassing the stress limit corresponding to rock microcracking $[4,15]$. Liu [16] studied the relations between rock brittleness and rock fragmentation efficiency by disc cutter and summarized the existing 35 different brittleness indexes, which can be classified into seven categories with respect to strength, strain, strain energy, hardness, Mohr envelope, etc. Although the rock brittleness has not yet been standardized [16], most previous studies stated that BI could be calculated by the equations in Table 1 and stated that it exhibited a good correlation with rock crushing performance $[16,17]$.

$$
\mathrm{IHI}=\frac{F_{\max }}{P} .
$$

As shown in Figure 1, natural rocks contain many joints and fissures [18], which are the important factors affecting rock mechanical properties. Gypsum has proven to be a good rock-like material for rock mechanics experiments and rock fragmentation behaviors $[19,20]$, while the artificial rock-like materials may be able to eliminate the testing errors caused by the inhomogeneity and discontinues of natural rocks. Therefore, quartz sand and high-strength $\alpha$-hemi-hydrated gypsum were used to prepared rock-like materials with different hardness and brittleness through different mass ratios. These rock-like materials can eliminate test errors caused by the inhomogeneity and discontinues of natural rocks. A series of indentation tests were conducted using a new indentation apparatus under confining stress conditions. In addition, the rock crushing models were calculated using a discrete element method code, i.e., Particle Flow Code in two dimensions (PFC2D). PFC2D is widely used in the simulation of rock crushing behaviors $[4,6,21]$. In this paper, the crushing models are calculated based on the UCS and BTS of the rock-like specimens. The cutting force and SE during fragmentation and failure patterns were investigated. The contribution of this study is that for the first time, the influence mechanism of rock-like materials' hardness and brittleness on their crushing behaviors and failure patterns is investigated by artificial rock-like materials and DEM. The artificial rock-like materials can eliminate the effects of natural rock's weak structure plane on study results. This investigation is of great significance for understanding the correlation between hardness and brittleness of rock materials and their fragmentation as well as failure patterns in rock crushing behaviors of underground engineering. 
TABLE 1: Brittleness indexes based on UCS and BTS [16].

\begin{tabular}{lc}
\hline Authors & Equations \\
\hline Altindag & $\mathrm{BI}_{1}=(\mathrm{UCS} \times \mathrm{BTS}) / 2$ \\
Hucka and Das & $\mathrm{BI}_{2}=\mathrm{UCS} / \mathrm{BTS}$ \\
Hucka and Das & $\mathrm{BI}_{3}=(\mathrm{UCS}-\mathrm{BTS}) /(\mathrm{UCS}+\mathrm{BTS})$ \\
Altindag & $\mathrm{BI}_{4}=\sqrt{\mathrm{UCS} \times \mathrm{BTS} / 2}$ \\
\hline
\end{tabular}

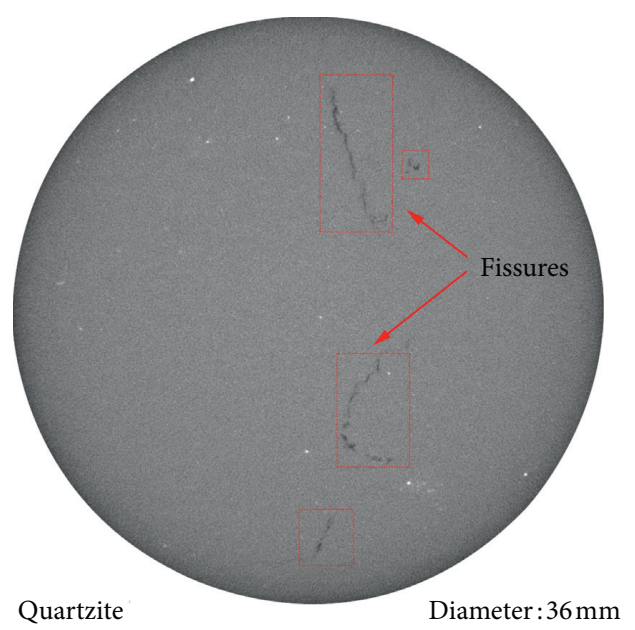

Figure 1: The fissures in natural rocks (CT images).

\section{Indentation Test with Different Confining Stress Levels}

2.1. Testing Apparatus and Specimen Preparation. In this paper, the indentation hardness testing is performed on a newly designed apparatus, which enables the indentation test of cylindrical specimen can be conducted under confining stress conditions. A schematic diagram of the newly designed apparatus is shown in Figure 2. The movement of indenter is controlled by a stepping motor. The penetration displacement is monitored by a linear variable differential transformer (LVDT), and the loading force is monitored by a $20 \mathrm{kN}$ load sensor. A volumepressure-controller (VPC) was used to load confining pressure. The conical indenter has a $90^{\circ}$ cone and $0.25 \mathrm{~mm}$ radius spherical tip. The bearing platform is a hollow cylinder, and the indenter can pass through the bearing platform. A free rock surface is prepared for indentationtesting on the top of rock specimen.

The detail of the mass ratios of rock-like materials is shown in Table 2 . The particle size of quartz sand is $0.18 \mathrm{~mm}$ (80 mesh sieve). As shown in Figure 3, the preparation process of specimens is as follows:

(1) According to the designed mass ratio, the ingredients were weighed, mixed, and stirred at a high speed for 3 minutes.

(2) The mixture was loaded into moulds and placed on the vibrostand to shake for 5 minutes.

(3) Specimens were removed from moulds after 2 hours and maintained at room temperature for 28 days. All the end faces of specimens were corrected according to ISRM recommendations. The ratio of retarder to gypsum is equal to $0.1 \%$; the ratio of defoamer to water is equal to $0.5 \%$.

As shown in Figure 3, the dimensions of specimens for uniaxial compressive testing were designed as $50 \mathrm{~mm}$ and $100 \mathrm{~mm}$ in diameter and height. Moreover, the dimensions of specimens for Brazilian splitting testing were designed as $50 \mathrm{~mm}$ and $25 \mathrm{~mm}$ in diameter and height. In the indentation tests, the size of the specimens affects the indentation test results and, as such, guidelines as observed from the following studies may be used for eliminating the size effects. According to the cavity expansion model (CEM) theory $[9,22,23]$, the ratio of the depth of the plastic zone induced by an axisymmetric indenter to the diameter of the rock specimen should be less than 0.167. Based on CEM theory, the ratio of the plastic zone depth-to-penetration depth could be calculated with the equations (2)-(7). In the equations, $r^{*}$ is the critical radius of the plastic zone, $n$ is a number characterizing the indenter geometry (for spherical and conical indenters, $n=2.0), K_{\mathrm{p}}$ is the passive coefficient, $K_{\mathrm{d}}$ is the dilatancy coefficient (here, dilatancy angle $\psi$ is equal to friction angle $\left.\varphi, \psi=\varphi=20^{\circ}\right), E_{1}$ is the Young's modulus of rocks $\left(E_{1}=3.63 \mathrm{GPa}\right), E_{2}$ is Young's modulus of indenter $\left(E_{2}=450 \mathrm{GPa}\right) . \quad v_{1}$ is Poisson's ratio of rocks $\left(v_{1}=0.16\right), v_{2}$ is Poisson's ratio of indenter $\left(v_{2}=0.27\right), \beta$ is the angle between the indenter and the free surface of the rock (for this indenter, $\beta=45^{\circ}$ ), $\sigma_{c}$ is the UCS of this rocklike material $\left(\sigma_{c}=18.53 \mathrm{MPa}\right)$, and $\alpha$ is the tip contact radius ( $\alpha=0.25 \mathrm{~mm}$ ). By substituting the parameters to equations (2)-(7), the plastic zone radius-to-sample diameter ratio is equal to 0.045 , which is less than 0.167 . Therefore, the dimension of rock sample with $36 \mathrm{~mm}$ in diameter is reasonable.

$$
\begin{gathered}
(1+\mu) \xi^{\left(n+K_{d}\right) / K_{d}}-\mu \xi^{\left(K_{p}-1\right) / K_{p}}=\gamma \\
\gamma=\frac{2^{3-2 n}\left(K_{p}+n\right) E_{1} \tan \beta}{(n+1) \pi^{2-n} \sigma_{c}\left(1+v_{1}\right)} \\
K_{d}=\frac{1+\sin \psi}{1-\sin \psi} ; \quad K_{p}=\frac{1+\sin \varphi}{1-\sin \varphi} \\
\mu=\frac{n \lambda K_{p}}{n\left(K_{p}+K_{d}\right)+(1-n) K_{p} K_{d}} \\
\lambda=\frac{\left(K_{p}-1\right)\left(K_{d}-1\right)+\left(1-2 v_{1}\right)\left[\left(K_{p}+1\right)\left(K_{d}+1\right)-(n-1) K_{p} K_{d}\right]}{(3-n)\left(1+v_{1}\right)^{n-1} K_{p}} \\
\xi=\frac{r_{*}}{\alpha} .
\end{gathered}
$$

2.2. Uniaxial Compressive Strength and Brazilian Tensile Strength Tests. In order to investigate the effects of hardness and brittleness on rocks fragmentation mechanism, the 


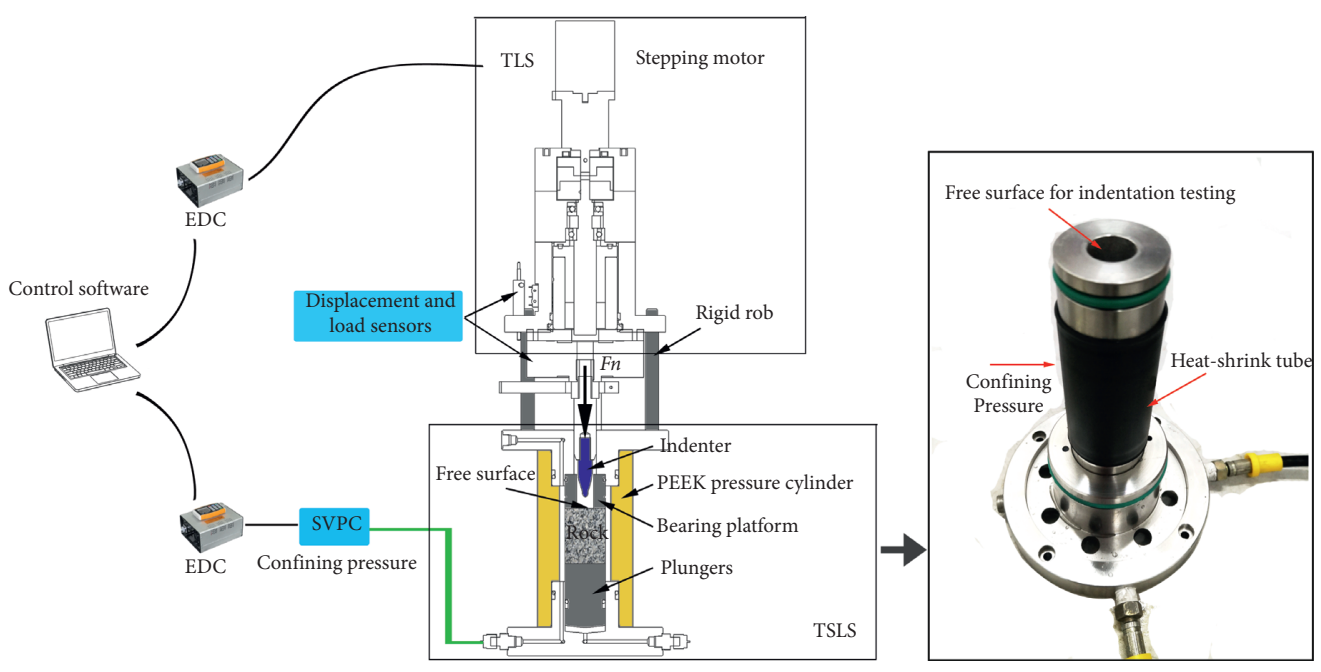

Figure 2: Schematic diagram of the newly designed triaxial testing system.

TABle 2: The mass ratio of ingredients of materials.

\begin{tabular}{lccc}
\hline No. & Gypsum & Quartz sand & Water \\
\hline$A$ & 10 & 1 & 4 \\
$B$ & 10 & 1.5 & 4 \\
$C$ & 10 & 2 & 4 \\
$D$ & 10 & 4 & 4 \\
\hline
\end{tabular}
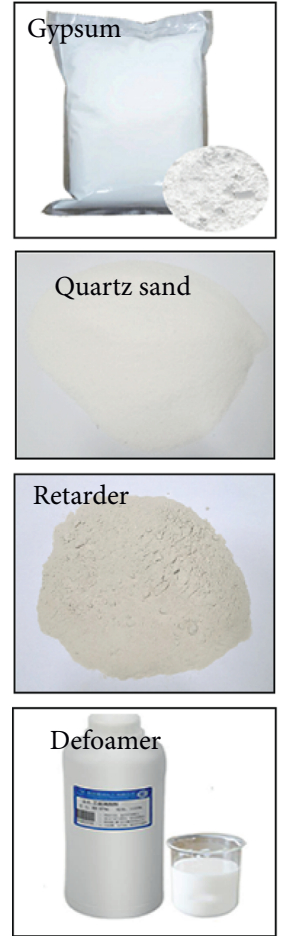

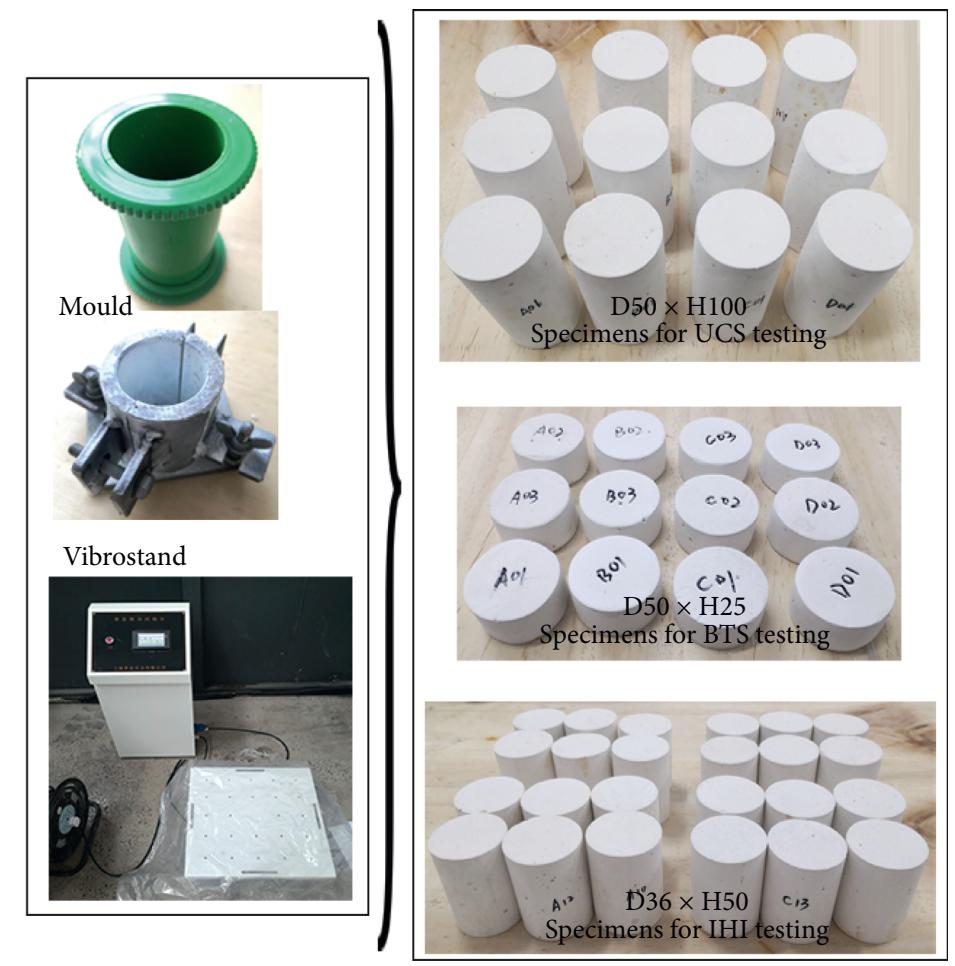

Figure 3: Preparation of the rock-like specimens. rock-like specimens with four different mass ratios were prepared in this study. A series of uniaxial compressive tests and Brazilian splitting tests were conducted to calculate the indexes of BI. The stress-strain curves of uniaxial compressive tests are shown in Figure 4, the displacementstress curves of Brazilian tensile tests are shown in Figure 5. It can be seen that the failure patterns all exhibited obvious plunge after peak stress, which suggested that 


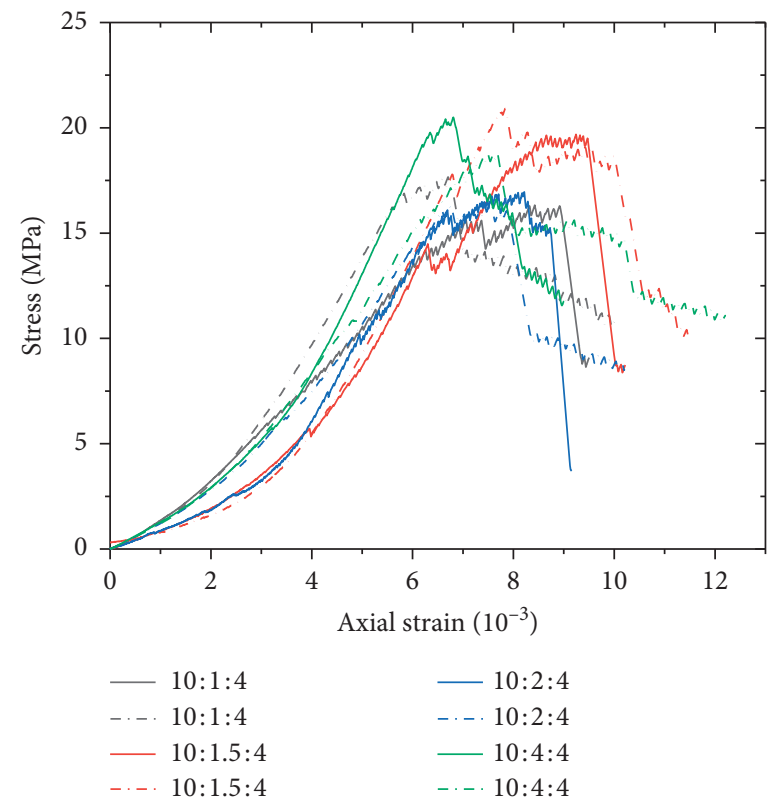

FIGURE 4: Stress-strain curves of rock-like materials of uniaxial compressive tests.

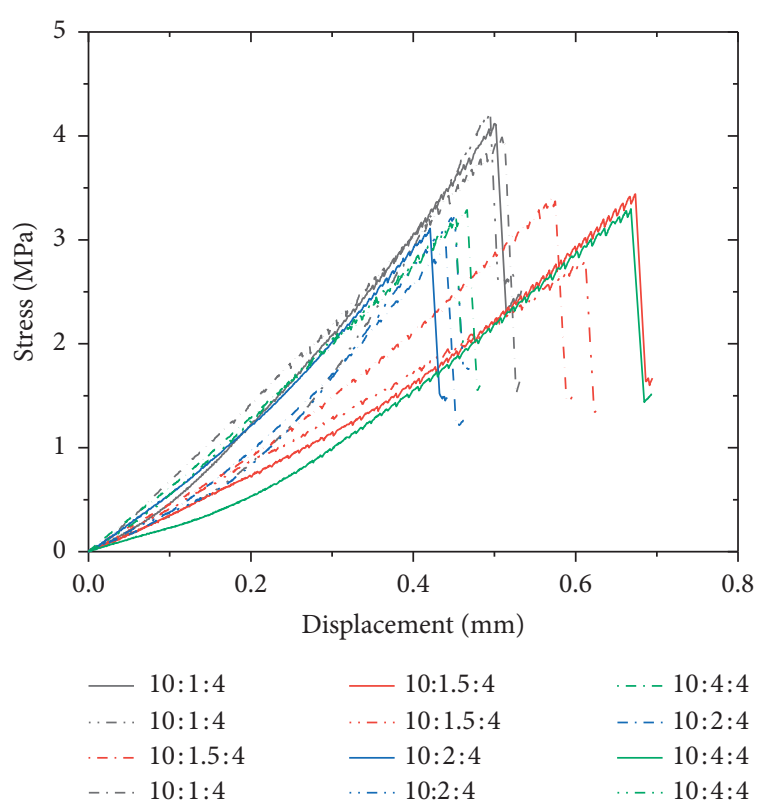

FIGURE 5: Displacement-stress curves of rock-like materials of Brazilian tensile tests.

these rock-like materials could characterize the brittle breaking characteristics of rocks. As shown in Table 3, the $\mathrm{BI}_{2}$ values range from 4.08 to 6.3 , and the $\mathrm{BI}_{3}$ values range from 0.62 to 0.73 . Figure 6 shows that the specimens in the uniaxial compression test mainly exhibited splitting failure induced by the propagation of vertical cracks. It also can be seen in the Brazilian tensile strength tests, as shown in Figure 7. Consequently, the rock numerical models used for investigating rock crushing behaviors are calculated based on the UCS, BTS, Young's modulus, and the failure patterns.
2.3. Indentation Tests under the Unconfined Condition and Confining Stress Condition. A series of indentation tests were conducted under unconfined stress and $5 \mathrm{MPa}$ confining stress conditions. The experimental results are shown in Figures 8 and 9. The velocity of the pick cutter is set to $1.0 \mathrm{~mm} / \mathrm{min}$ according to Wang's studies [8]. The confining stress restrained the propagation of vertical cracks. Since the slope of the curve is unstable at the initial stage of the indentation test, the slope of the fitted line near the maximum load is used as the indentation hardness, as shown in Figure 8. Moreover, the slope of the fitted line at the penetration displacement of $6 \mathrm{~mm}$ is used as the IHI under $5 \mathrm{MPa}$ confining stress conditions. The IHIs under $5 \mathrm{MPa}$ confining stress conditions are always less than that under unconfined stress conditions. According to the results in Table 3 and failure patterns in Figure 10, it can be seen that propagating crack length has negative correlation with IHI. As shown in Figures 10 and 11, there existed a compaction stage at the beginning of indentation test, and then the expansion of the crushed rocks induced the initiation and propagation of tension cracks. It can be seen in Figure 12 that the index $\mathrm{BI}_{2}[16]$ increased with the increase of IHI with a high correlation coefficient of 0.999 . As shown in Figure 13, $\mathrm{BI}_{3}$ exhibited the same change law with $\mathrm{IHI}$ while $\mathrm{BI}_{1}$ and $\mathrm{BI}_{4}$ did not show a prominent correlation with IHI. The Figure 14 shows that the IHI has evident positive correlation with UCS. Therefore, the index $\mathrm{BI}_{2}$ is more suitable for the brittleness study in this paper.

\section{Discrete Element Analysis of Crushing}

3.1. Microparameters Calculating Based on UCS and BTS. In order to investigate the relation between hardness, brittleness, and rock crushing behaviors, the numerical models of rock-like materials were built through the flat- 
TABLE 3: The experimental results of rock-like materials.

\begin{tabular}{|c|c|c|c|c|c|c|c|c|}
\hline No. & UCS (MPa) & BTS (MPa) & $\mathrm{BI}_{1}\left(\mathrm{MPa}^{2}\right)$ & $\mathrm{BI}_{2}$ & $\mathrm{BI}_{3}$ & $\mathrm{BI}_{4}(\mathrm{MPa})$ & IHI $\left(\mathrm{kN} \cdot \mathrm{mm}^{-1}\right)$ unconfined & IHI $\left(\mathrm{kN} \cdot \mathrm{mm}^{-1}\right) 5 \mathrm{MPa}$ confining stress \\
\hline$A$ & 16.98 & 4.04 & 34.30 & 4.08 & 0.62 & 5.86 & 0.8769 & 1.1545 \\
\hline$B$ & 20.29 & 3.22 & 32.67 & 6.30 & 0.73 & 5.72 & 1.1545 & 1.4264 \\
\hline C & 16.70 & 3.09 & 25.80 & 5.40 & 0.69 & 5.08 & 0.9318 & 1.7456 \\
\hline$D$ & 20.16 & 3.26 & 32.86 & 6.18 & 0.72 & 5.73 & 1.1119 & 1.7558 \\
\hline
\end{tabular}
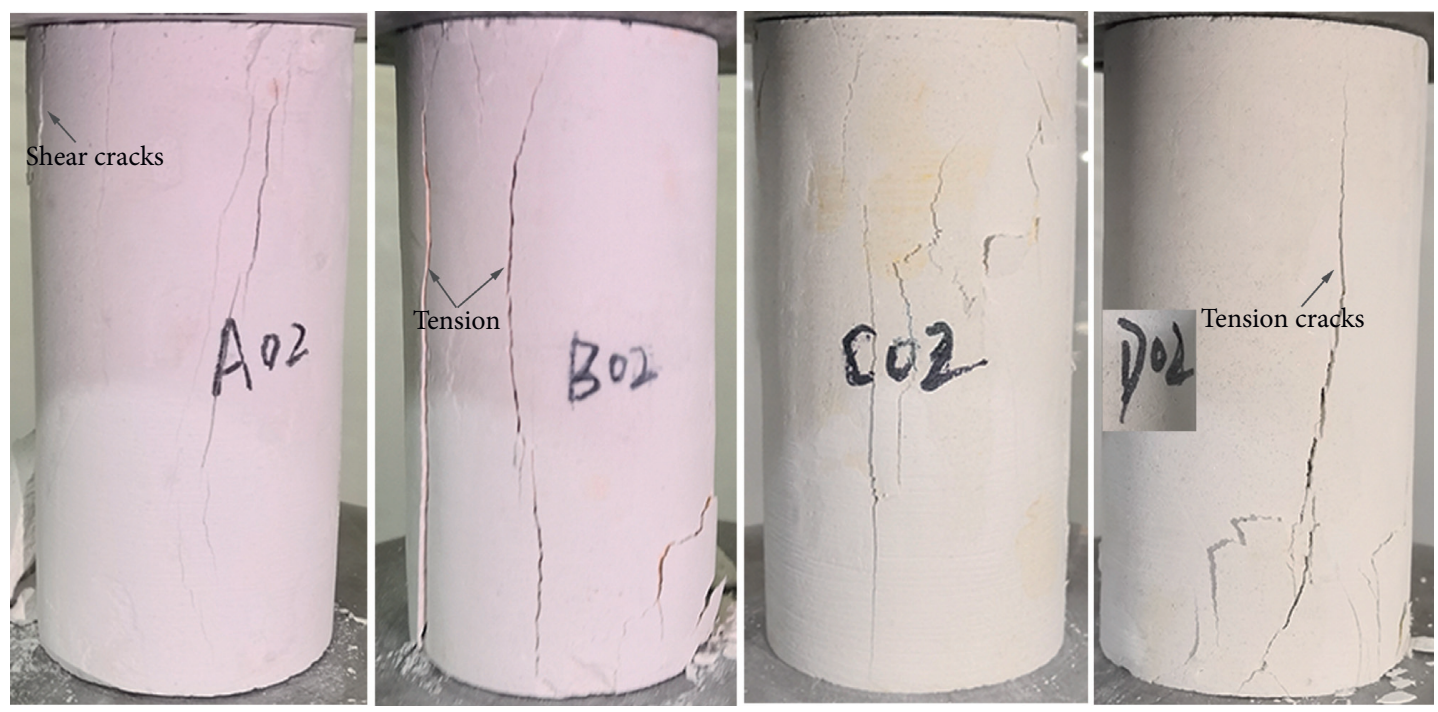

FIGURE 6: Failure patterns of specimens in uniaxial compressive tests.
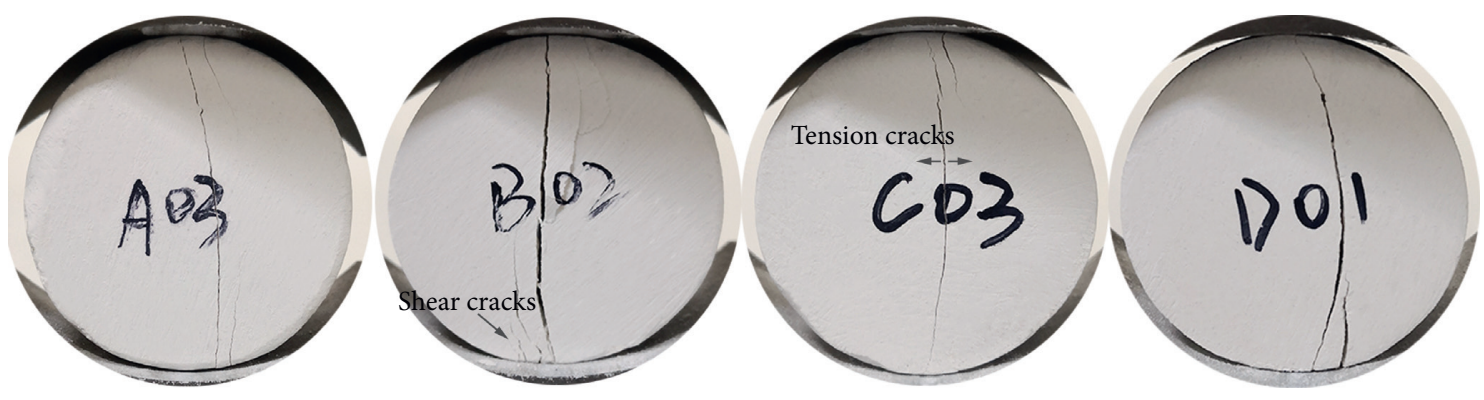

FIGURE 7: Failure patterns of specimens in Brazilian tensile tests.

joint contact model (FJM) [24] in PFC2D [25]. As shown in Figure 15, the flat-joint contact simulates the behavior of an interface between two notional surfaces, each of which is connected rigidly to a piece of body. The particles of a flatjointed material are considered as faced grains, each of which is depicted as a core and a number of skirted faces. The interface is evenly discretized into several elements. According to previous researchers' work, the numerical models of FJM is found to closely match real rocks' macroproperties [26]. Therefore, the numerical models of rock-like materials were all calculated utilizing FJM in this study.

According to the mechanical parameters in Table 3 and the calibration procedure in Figure 16, the calculating results are shown in Figure 17. The microparameters can be calculated as shown in Table 4 . The ratio of maximum to minimum diameter is set to 1.66 [27]. Table 5 shows the comparison of results obtained from numerical modeling and experimental tests. It suggested that the modeling results agree well with the results obtained from physical experiments. It can be seen that the failure patterns of numerical results exhibited the same characteristics with that of experimental results as shown in Figure 6. The different errors of all the parameters can be controlled within $\pm 3.5 \%$. In Figure 17 , the blue cracks represent the shear cracks and the green cracks represent the tension cracks. Figures $17(\mathrm{a})-17(\mathrm{~d})$ are the stress-strain curves and failure patterns of UCS tests, and Figure 17(e)-17(h) are the stress-strain curves and failure patterns of BTS tests. 


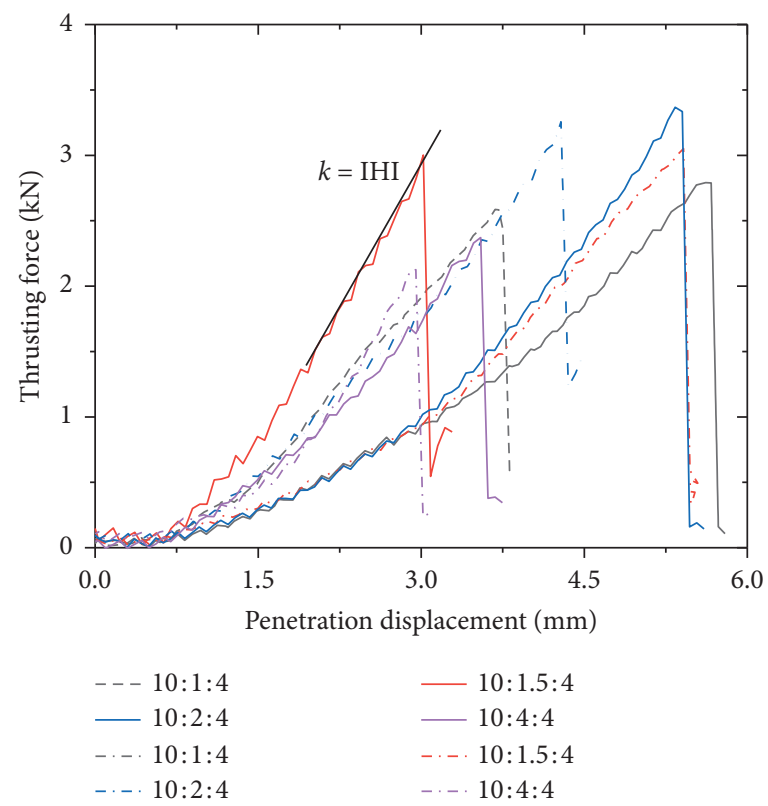

FIGURE 8: Displacement-force curves of indentation tests under unconfined stress conditions.

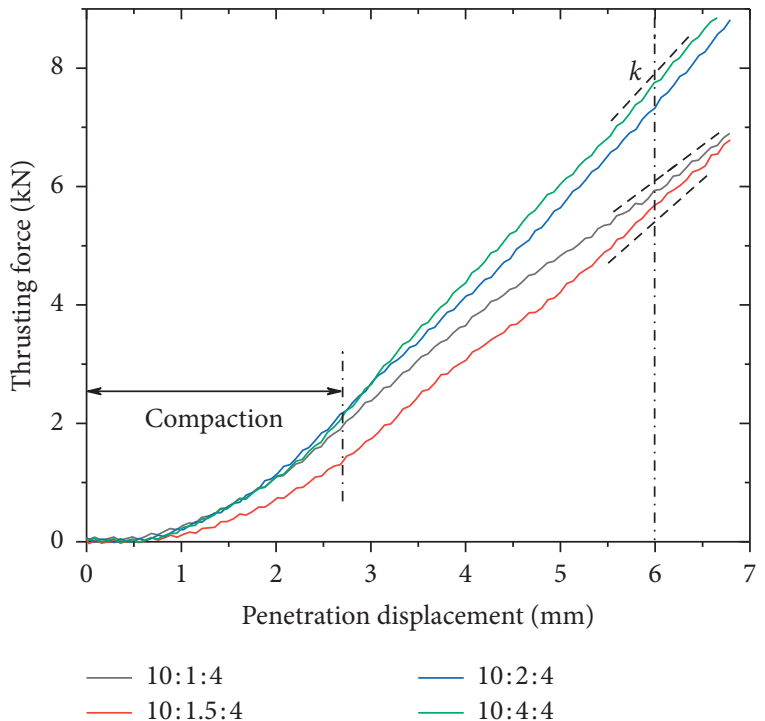

FIgURE 9: Displacement-force curves of indentation tests under $5 \mathrm{MPa}$ confining stress conditions.

\subsection{Effects of Hardness and Brittleness on Rock Crushing} Behaviors. In the numerical crushing tests, the numerical models of rock-like materials were established according to the experimental results (i.e., UCS, BTS, and Young's modulus). More microscopic crushing characteristics can be observed in numerical analysis. The SE can be calculated by equation (8), where $F_{i}$ is the recorded crushing force data and $V_{\text {chippings }}$ is the total volume of crushing chippings. Since the SE is positively related to UCS, the normalized $\overline{\mathrm{SE}}$ is proposed by equation (9). The failure patterns of crushing chippings of rock-like materials are shown in Figures 18 and 19.

$$
\begin{aligned}
& \mathrm{SE}=\frac{\int_{0}^{d} F_{i} \mathrm{~d} x}{V_{\text {chippings }}}, \\
& \overline{\mathrm{SE}}=\frac{\mathrm{SE}}{\mathrm{UCS}} .
\end{aligned}
$$

Figure 20 shows that $\overline{\mathrm{SE}}$ is negatively correlated with IHI. The normalized specific energy $\overline{\mathrm{SE}}$ decreased exponentially with the increase of $\mathrm{BI}_{2}$ with a high correlation coefficient of 0.9217, as shown in Figure 21. Figure 18 shows that the main failure patterns of crushing behaviors keep in line with the failure patterns of rock tests in Figure 17. According to the numerical results of crushing force in Table 6 , it can be seen that the mean of crushing forces under unconfined stress conditions is larger than that under $5 \mathrm{MPa}$ confining stress conditions in the crushing tests of material $A$ and $C$, while the standard deviation values of crushing forces are opposite. Comparing Figures 18 and 19, it can be seen that the propagation depth of cracks was restrained, but the index $\overline{\mathrm{SE}}$ increased. Under $5 \mathrm{MPa}$ confining stress conditions, $\overline{\mathrm{SE}}$ is negatively correlated with IHI; the normalized specific energy $\overline{\mathrm{SE}}$ decreased with the increase of BII* with a high correlation coefficient of 0.98256, as shown in Figures 22 and 23.

The numerical results show that the average size of chippings of materials $B$ and $D$ are larger than that of materials $A$ and $C$. Moreover, the propagation length of tensile cracks is larger than that of shear cracks. As shown in Tables 7 and 8 , the number of shear cracks of materials $A$ and $C$ is greater than that of materials $B$ and $D$, but the number of tension cracks of materials $A$ and $C$ is less than that of materials $B$ and $D$. Therefore, the failure patterns of rock-like materials with higher brittleness are more prone to tensile failure in the crushing testing. 


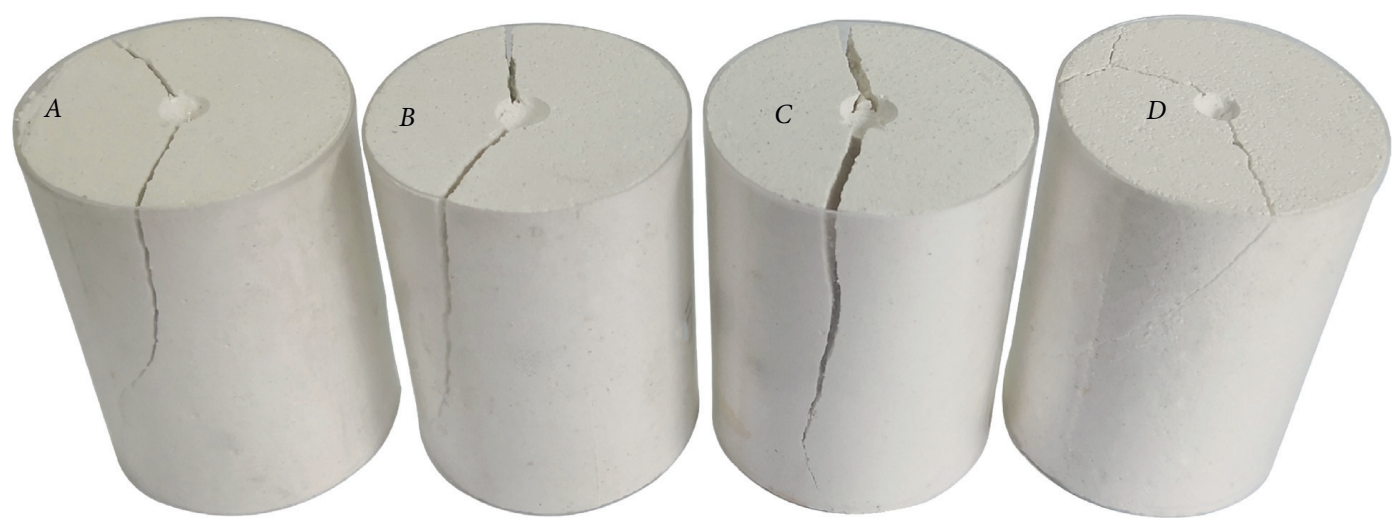

FIGURE 10: Failure patterns of specimens in indentation tests under unconfined stress conditions.

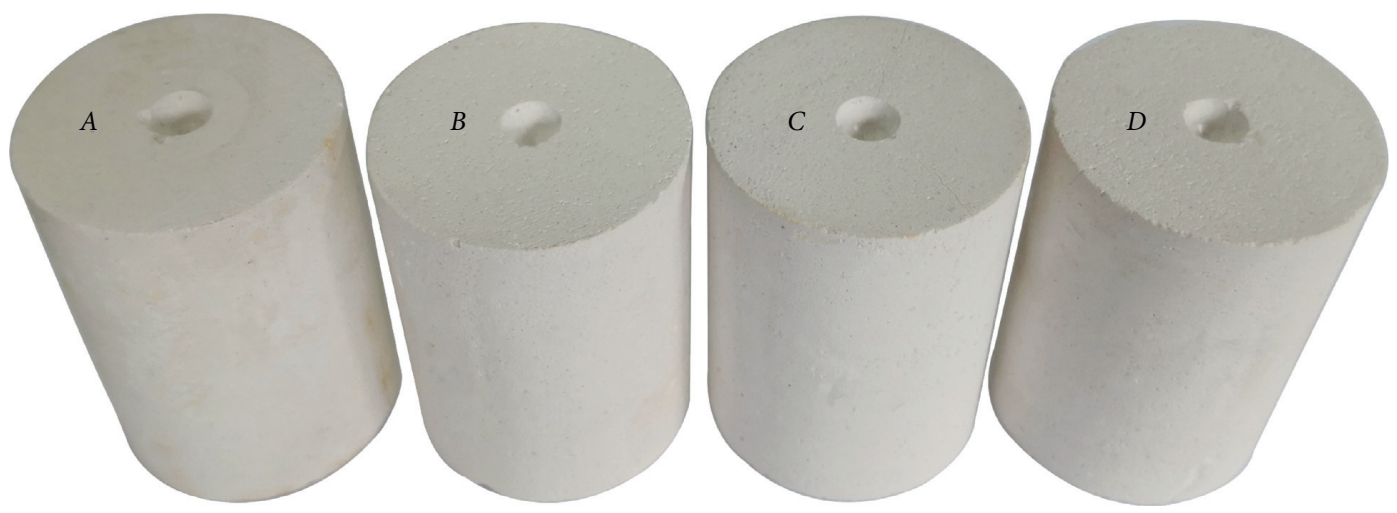

FIGURE 11: Failure patterns of specimens in indentation tests under $5 \mathrm{MPa}$ confining stress conditions.

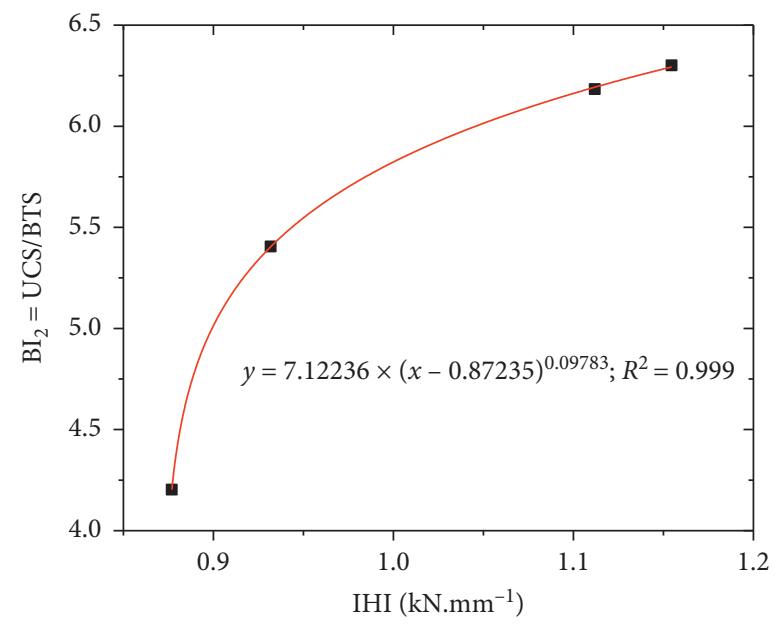

FIgURE 12: Relationship between IHI and $\mathrm{BI}_{2}$ under unconfined stress conditions.

$$
R_{e}=2 \times \sqrt{\frac{c(\bar{d} / 2)^{2}}{1-\rho}} .
$$

In equation (10), $R_{e}$ is the equivalent diameter of chipping, $c$ is the number of particles of chipping, and $\bar{d}$ is the mean diameter of particle. The pore ratio $\rho$ of the numerical model is 0.12 . Comparing $A$ and $C$, it is found that the larger the indentation hardness, the larger the proportion of the particles (equivalent diameter at $0-0.008 \mathrm{~m}$ range) in the cumulative gradation curve, as 


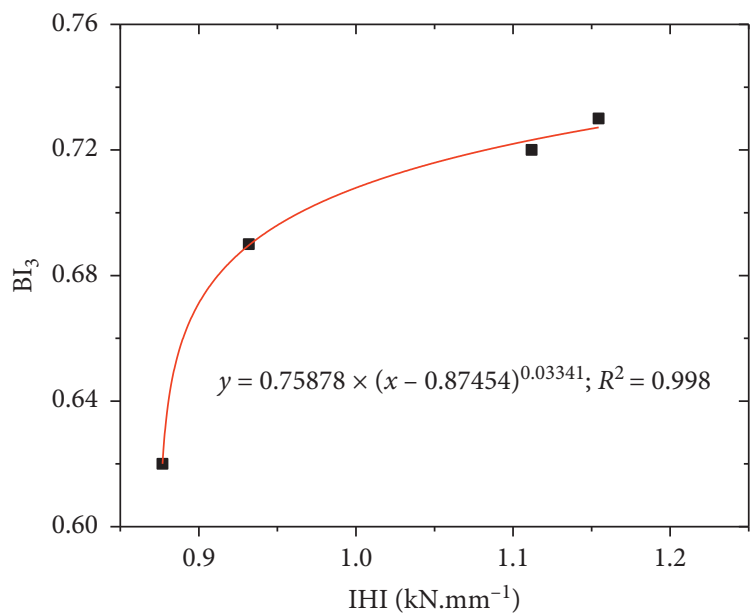

FIgURE 13: Relationship between IHI and $\mathrm{BI}_{3}$ under unconfined stress conditions.

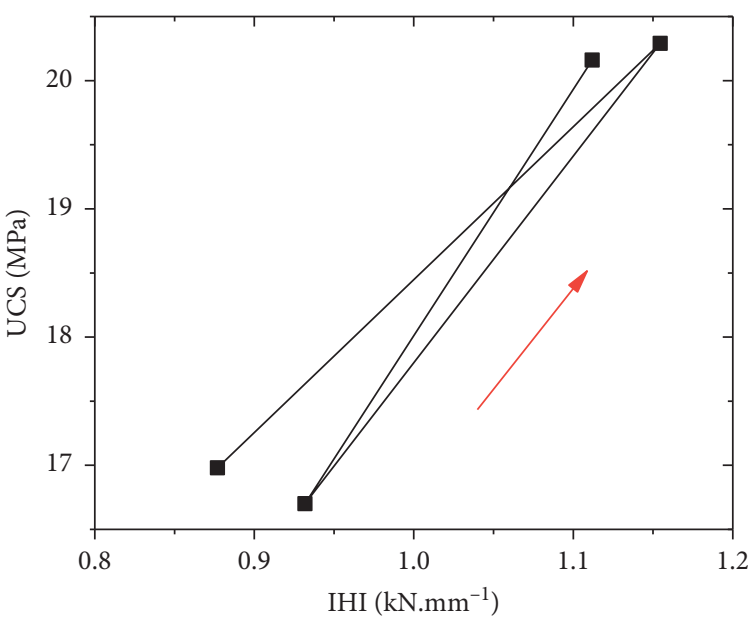

FIGURE 14: The correlation between IHI and UCS.

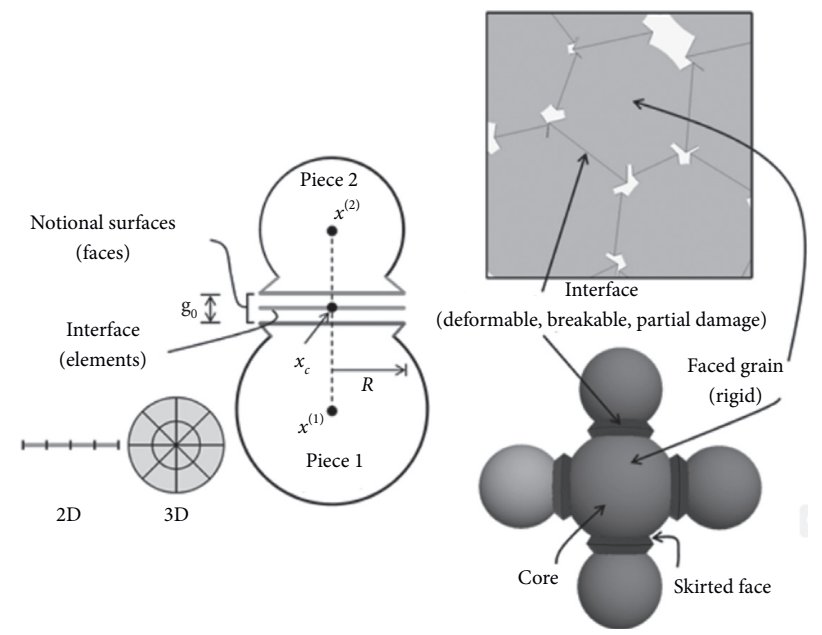

FIgURE 15: Mechanism of the interaction between particles in FJM [25]. 


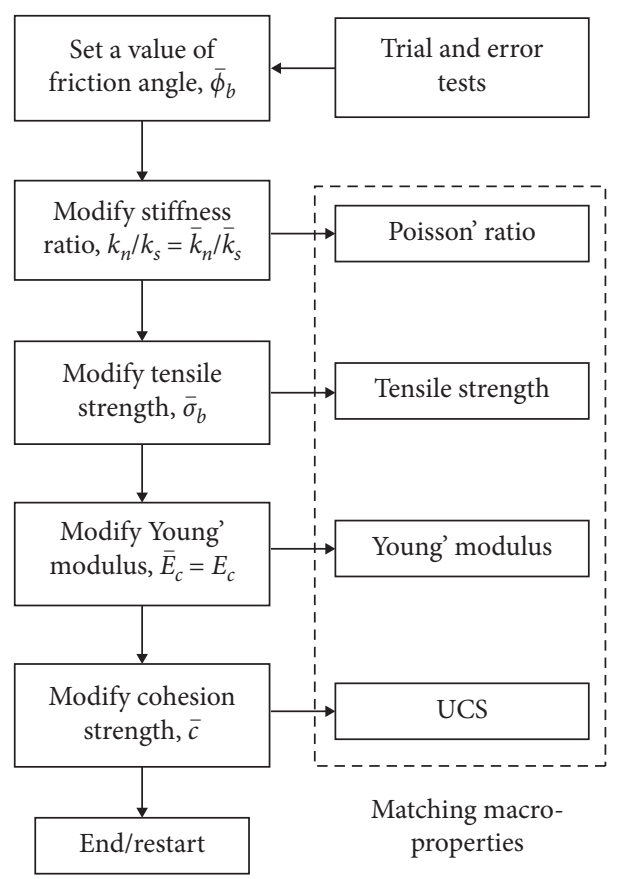

FIgURE 16: The microparameters calibration procedure of numerical models.

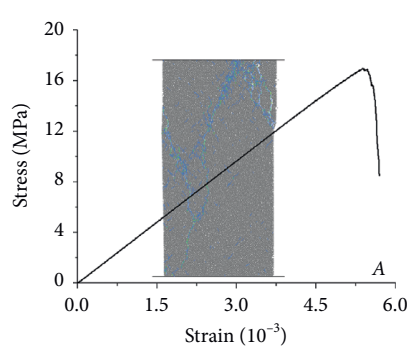

— UCS

(a)

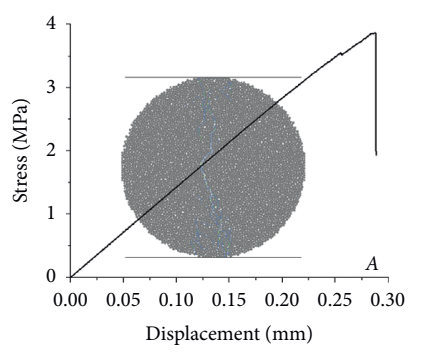

— BTS

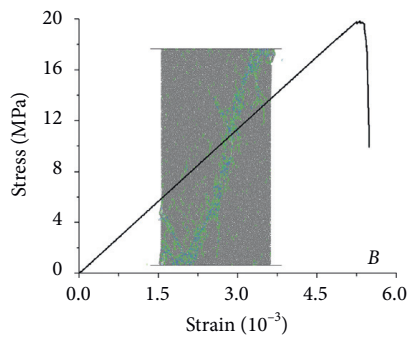

— UCS

(b)

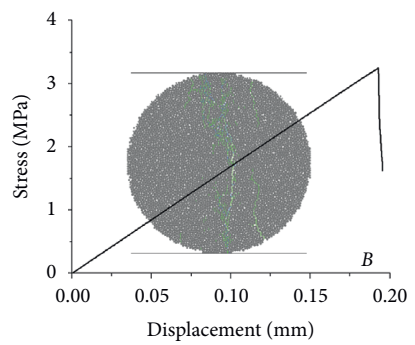

— BTS

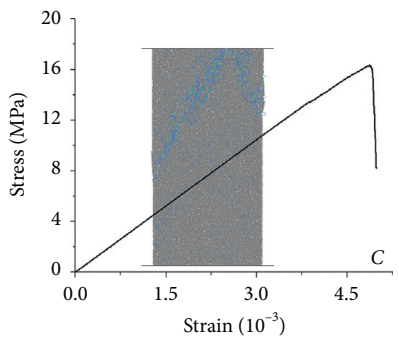

— UCS

(c)

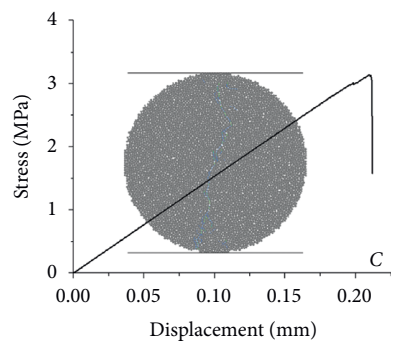

— BTS

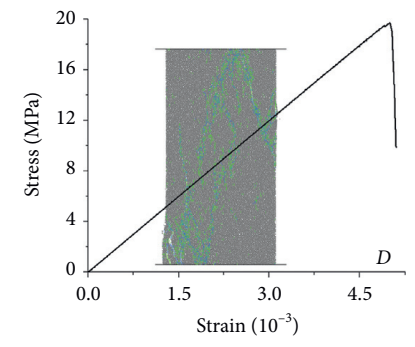

— UCS

(d)

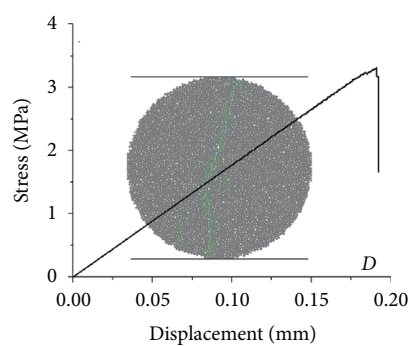

— BTS

(e)

(f)

(g)

(h)

FIgURE 17: The calculating results of numerical modeling (from left to right are materials $A, B, C$, and $D$ ).

TABLE 4: The microparameters used in this PFC2D model.

\begin{tabular}{|c|c|c|c|c|}
\hline Micro-parameters & $A$ & $B$ & C & $D$ \\
\hline Minimum disk diameter $d_{\min }(\mathrm{mm})$ & 0.5 & 0.5 & 0.5 & 0.5 \\
\hline Maximum to minimum disk diameter ratio $d_{\max } / d_{\min }$ & 1.66 & 1.66 & 1.66 & 1.66 \\
\hline Young's modulus of particle and bond $E_{c}=\bar{E}_{c}(\mathrm{GPa})$ & 3.11 & 3.65 & 3.37 & 3.87 \\
\hline Ratio of normal to shear stiffness of particle and bond $k_{n} / k_{s}=\bar{k}_{n} / \bar{k}_{s}$ & 1.6 & 1.6 & 1.6 & 1.6 \\
\hline Element number, $N$ & 4 & 4 & 4 & 4 \\
\hline Particle friction coefficient $\mu$ & 0.7 & 0.7 & 0.7 & 0.7 \\
\hline Diameter of particle $d(\mathrm{~mm})$ & 0.36 & 0.36 & 0.36 & 0.36 \\
\hline Parallel-bond tensile strength $\bar{\sigma}_{c}(\mathrm{MPa})$ & 17.05 & 6.62 & 13.8 & 6.94 \\
\hline Parallel-bond cohesion strength $\bar{c}(\mathrm{MPa})$ & 8.2 & 12.55 & 7.55 & 11.16 \\
\hline Parallel-bond friction angle $\bar{\varphi}\left({ }^{\circ}\right)$ & 13 & 13 & 13 & 13 \\
\hline
\end{tabular}


TABLE 5: Comparison of results obtained from numerical modeling and experimental tests.

\begin{tabular}{|c|c|c|c|c|c|c|c|c|c|c|c|c|}
\hline \multirow{2}{*}{$\begin{array}{l}\text { Material } \\
\text { Item }\end{array}$} & \multicolumn{3}{|c|}{$A$} & \multicolumn{3}{|c|}{$B$} & \multicolumn{3}{|c|}{$C$} & \multicolumn{3}{|c|}{$D$} \\
\hline & Exp. & Num. & Diff. & Exp. & Num. & Diff. & Exp. & Num. & Diff. & Exp. & Num. & Diff. \\
\hline UCS (MPa) & 16.98 & 17.0 & $0.12 \%$ & 20.29 & 19.88 & $-2.02 \%$ & 16.70 & 16.40 & $-1.80 \%$ & 20.16 & 19.76 & $-1.98 \%$ \\
\hline BTS (MPa) & 4.04 & 3.90 & $-3.47 \%$ & 3.22 & 3.25 & $0.93 \%$ & 3.09 & 3.14 & $1.62 \%$ & 3.26 & 3.30 & $2.76 \%$ \\
\hline$E_{1}(\mathrm{GPa})$ & 3.22 & 3.22 & $0.0 \%$ & 3.80 & 3.80 & $0.0 \%$ & 3.49 & 3.49 & $0.0 \%$ & 3.99 & 4.00 & $0.25 \%$ \\
\hline
\end{tabular}
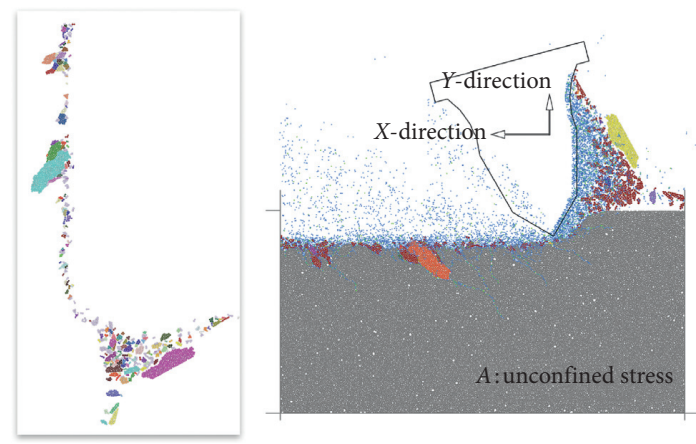

(a)
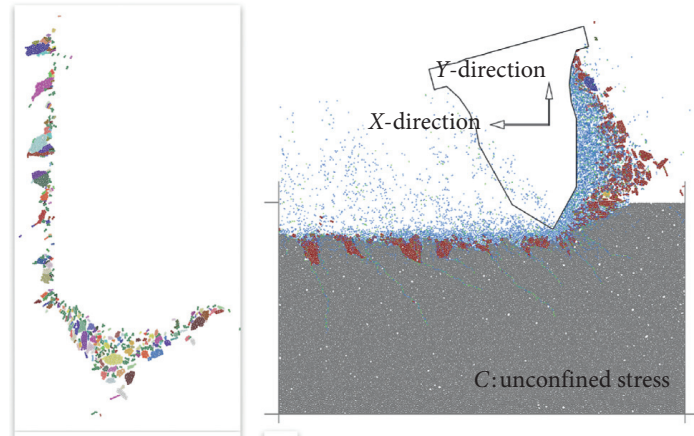

(c)
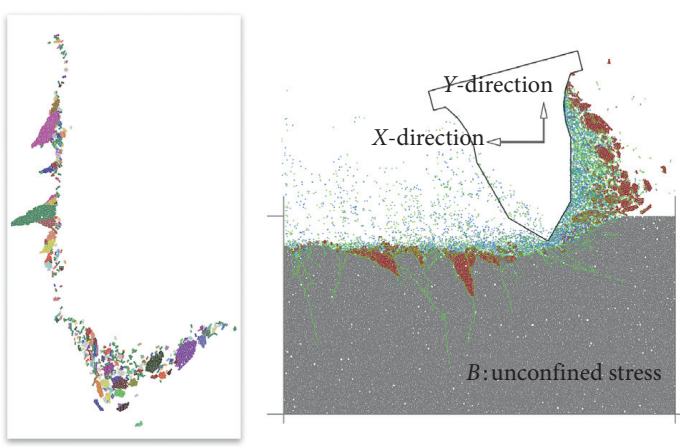

(b)
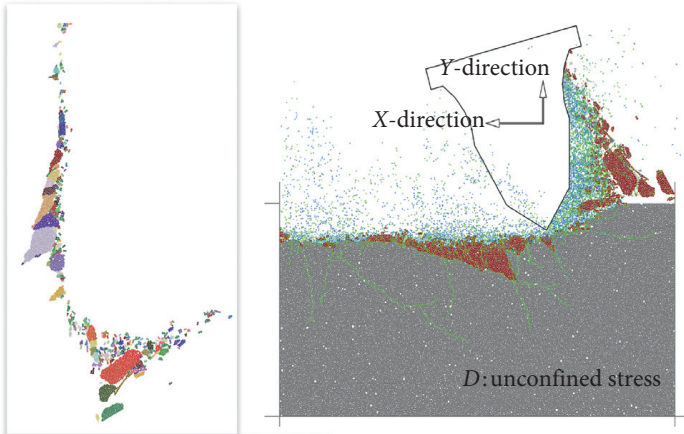

(d)

FIGURE 18: The failure patterns of crushing chippings of rock-like materials under unconfined conditions.

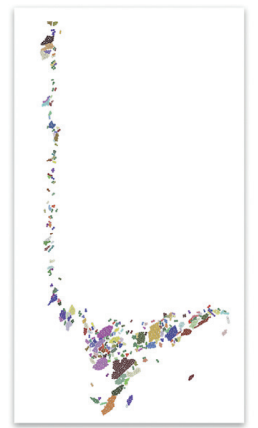

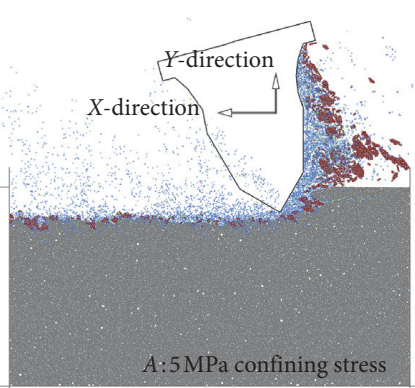

(a)

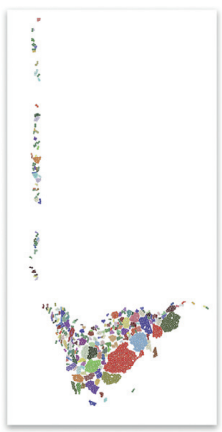

FIGURE 19: Continued.

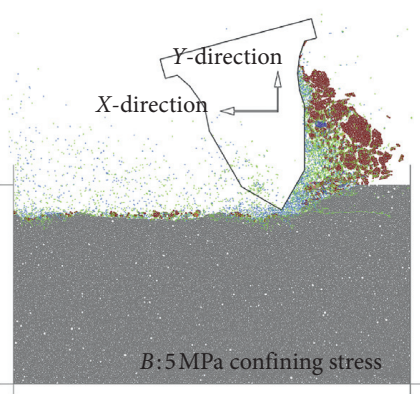

(b) 


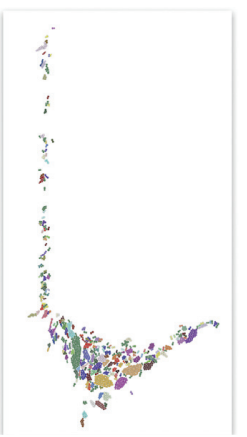

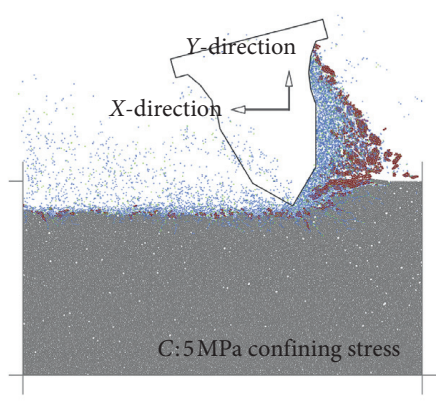

(c)
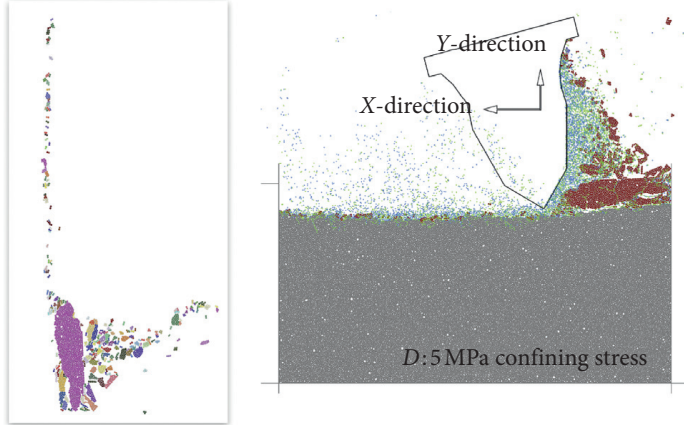

(d)

FIGURE 19: The failure patterns of crushing chippings of rock-like materials under $5 \mathrm{MPa}$ confining stress conditions.

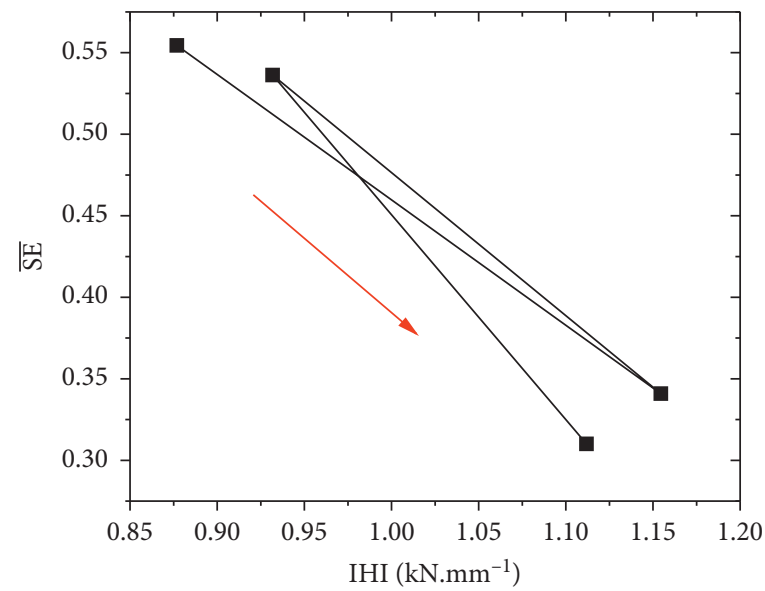

FIgURE 20: The relationship between $\overline{\mathrm{SE}}$ and IHI.

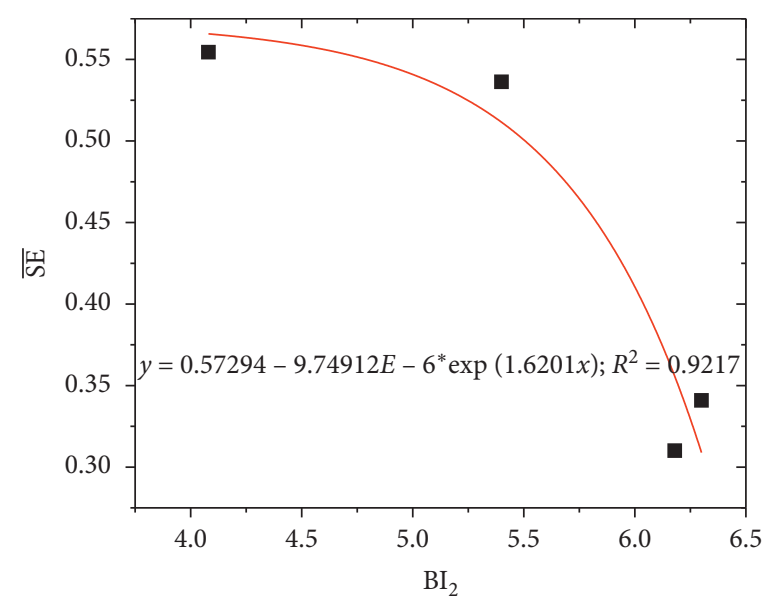

Figure 21: The relationship between $\overline{\mathrm{SE}}$ and brittleness. 
TABLE 6: The mean and standard deviation values of crushing force data.

\begin{tabular}{|c|c|c|c|c|c|c|c|c|c|}
\hline \multirow{2}{*}{\multicolumn{2}{|c|}{$\begin{array}{l}\text { Crushing force }(\mathrm{kN}) \\
\text { Force direction }\end{array}$}} & \multicolumn{2}{|c|}{ Crushing forces of $A$} & \multicolumn{2}{|c|}{ Crushing forces of $B$} & \multicolumn{2}{|c|}{ Crushing forces of $C$} & \multicolumn{2}{|c|}{ Crushing forces of $D$} \\
\hline & & $X$-direction & $Y$-direction & $X$-direction & $Y$-direction & $X$-direction & $Y$-direction & $X$-direction & $Y$-direction \\
\hline \multirow{2}{*}{$\begin{array}{l}\text { Unconfined } \\
\text { stress conditions }\end{array}$} & Mean & 159.05 & 92.96 & 123.01 & 72.03 & 161.20 & 93.04 & 116.68 & 68.20 \\
\hline & $\begin{array}{l}\text { Standard } \\
\text { deviation }\end{array}$ & 81.52 & 48.60 & 88.45 & 51.24 & 86.68 & 50.18 & 81.83 & 48.00 \\
\hline \multirow{2}{*}{$\begin{array}{l}5 \mathrm{MPa} \text { confining } \\
\text { stress conditions }\end{array}$} & Mean & 154.43 & 92.12 & 89.37 & 51.67 & 152.98 & 88.56 & 122.44 & 72.73 \\
\hline & $\begin{array}{l}\text { Standard } \\
\text { deviation }\end{array}$ & 89.58 & 56.27 & 76.53 & 46.99 & 95.08 & 55.59 & 73.08 & 44.72 \\
\hline
\end{tabular}

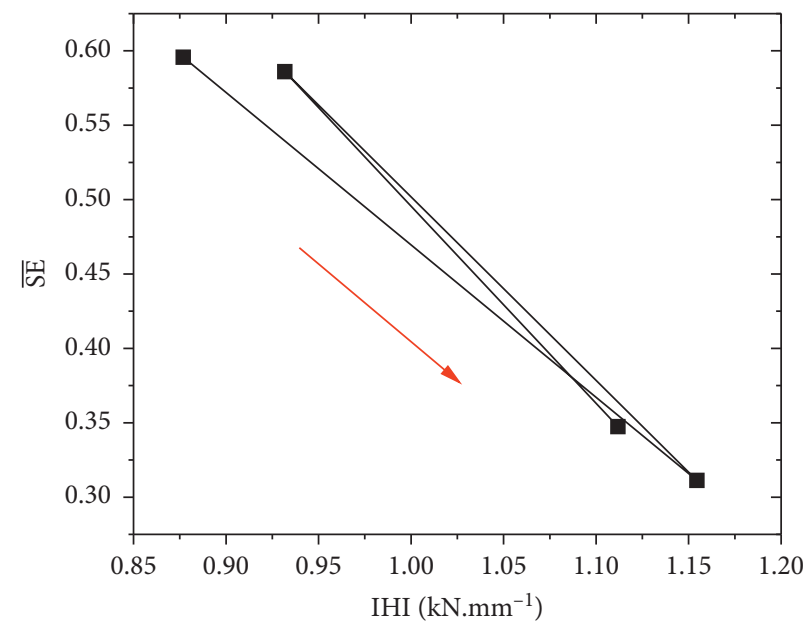

FIgURE 22: The relationship between $\overline{\mathrm{SE}}$ and IHI.

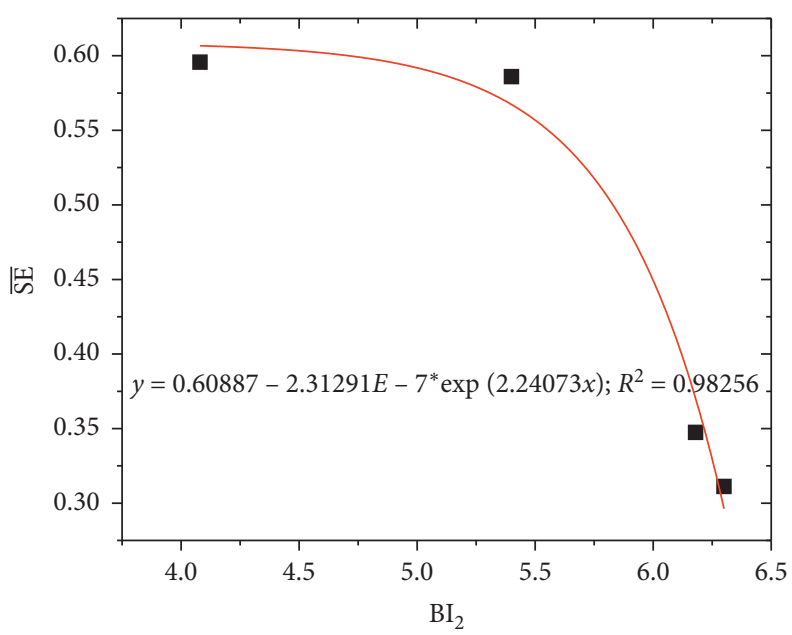

FIgURE 23: The relationship between $\overline{\mathrm{SE}}$ and brittleness. 
TABLE 7: The orientation and quantity of microcracks in rock crushing tests (unconfined conditions).

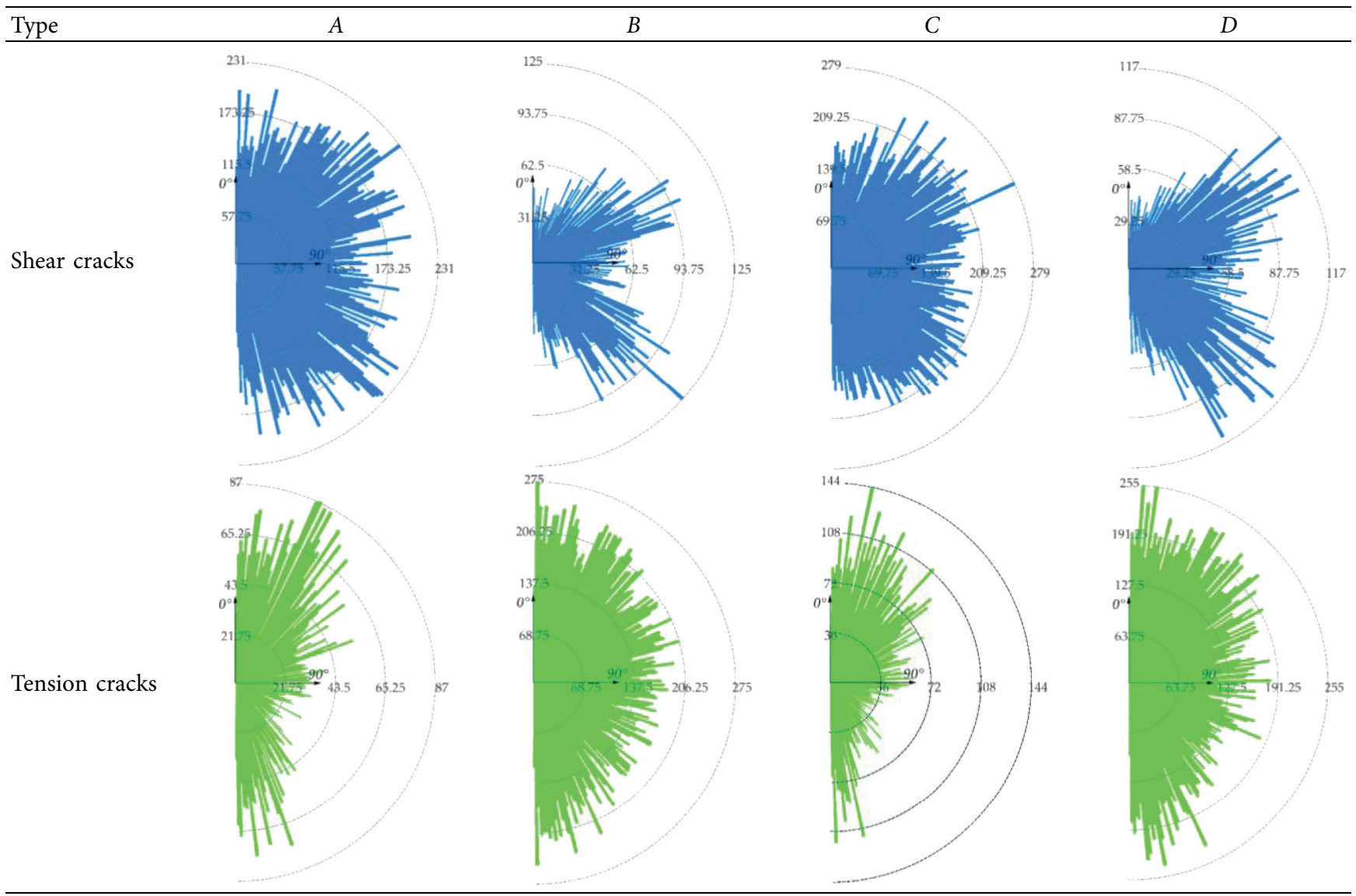

TABLE 8: The orientation and quantity of microcracks in rock crushing tests (5 MPa confining stress conditions).

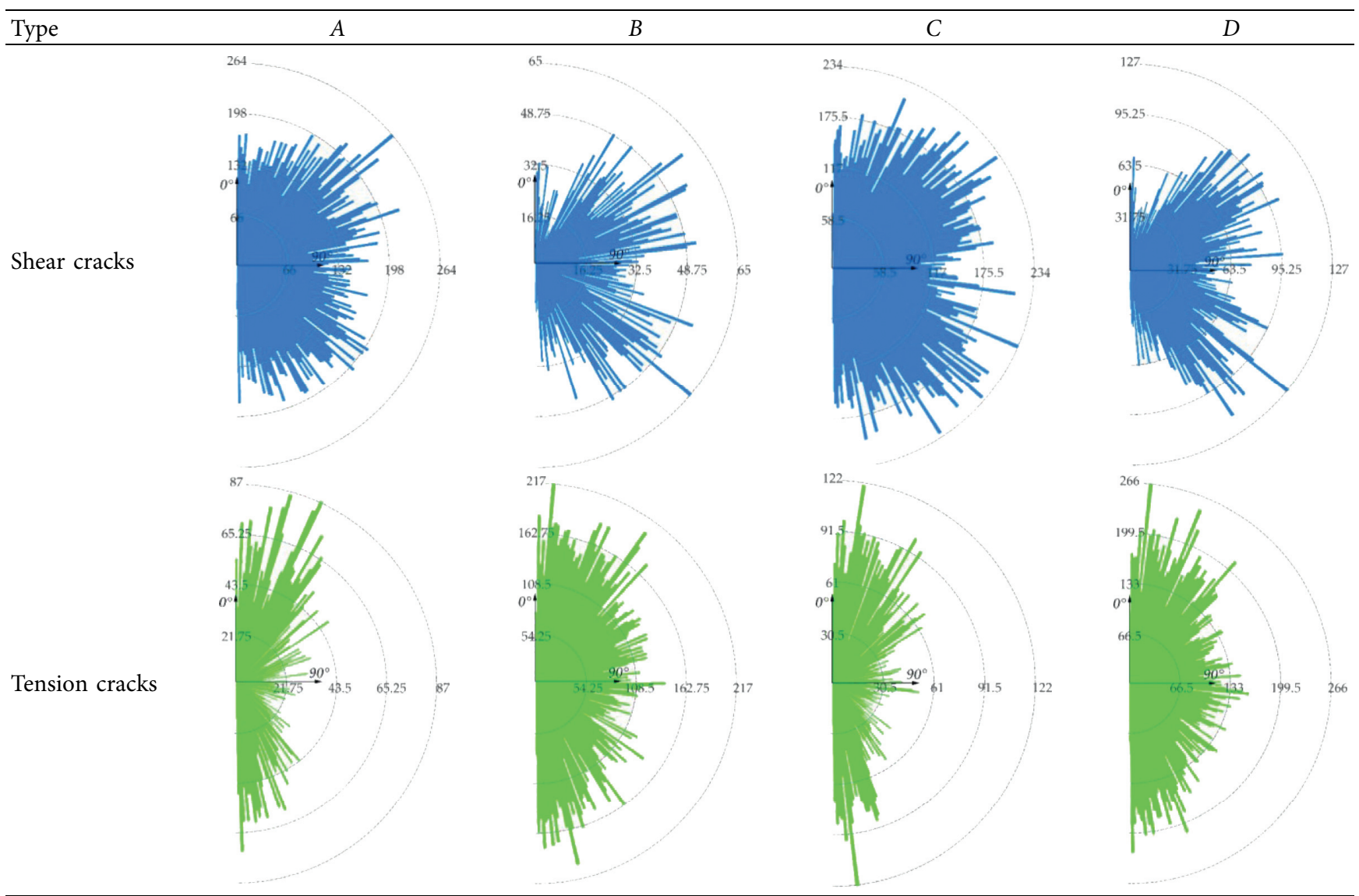




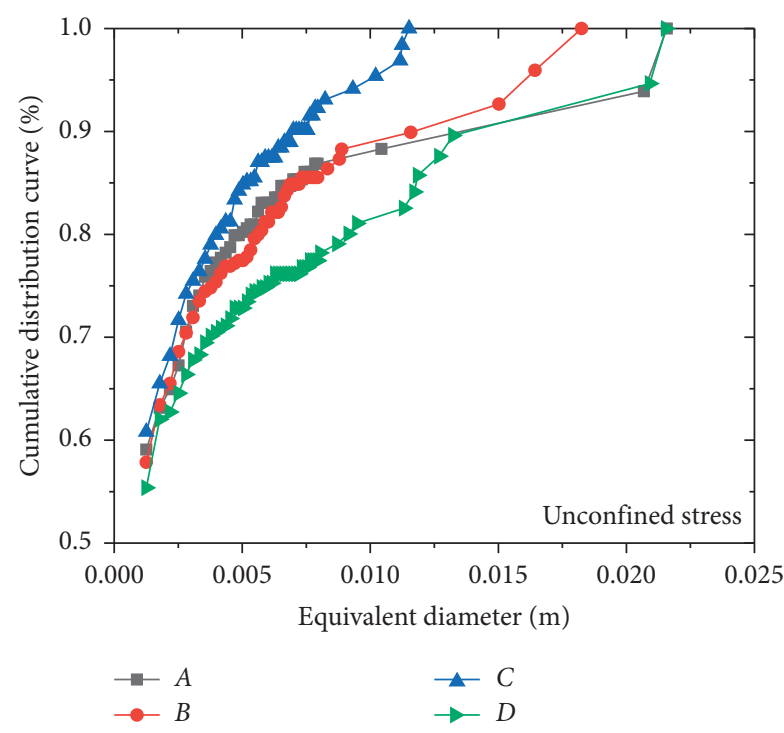

Figure 24: The distribution of equivalent diameter of rock chippings under unconfined stress conditions.

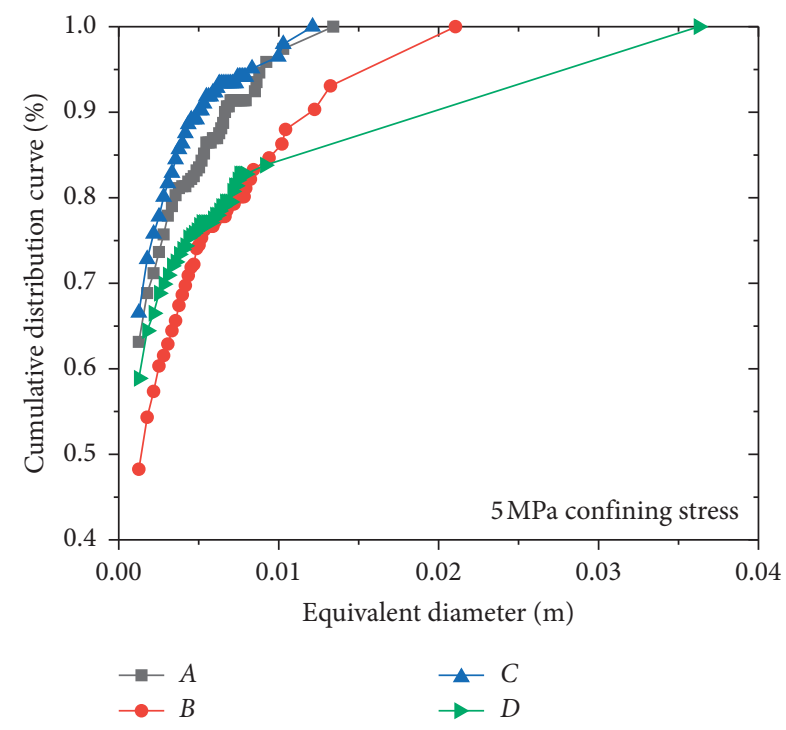

Figure 25: The distribution of equivalent diameter of rock chippings under $5 \mathrm{MPa}$ confining stress conditions.

shown in Figures 24 and 25 . The same is true between $B$ and $D$.

\section{Conclusions}

In this paper, quartz sand and high-strength $\alpha$-hemi-hydrated gypsum were prepared to make rock-like materials with different hardness and brittleness through different mass ratios. Gypsum has proven to be a good rock-like material for rock mechanics experiments and rock fragmentation behaviors. The numerical models were calculated based on the mechanical parameters of those rock-like materials. The influence mechanism of indentation hardness and brittleness of rock-like materials on their crushing behaviors was investigated using the DEM, i.e., PFC2D. The main conclusions can be drawn as follows.

The index $\mathrm{BI}_{2}$ increased exponentially with the increase of IHI with high-correlation coefficient. The index IHI has evident positive correlation with UCS. Hardness and brittleness can be used as important indexes to characterize the mechanical properties and failure patterns of rock materials. According to the numerical results of the crushing tests, the normalized specific energy $\overline{\mathrm{SE}}$ is negatively correlated with IHI. $\overline{\mathrm{SE}}$ decreased exponentially with the increase of $\mathrm{BI}_{2}$. The failure patterns of rock-like materials with higher brittleness are more prone to tensile failure in the crushing testing.

This investigation is of great significance for understanding the correlation between hardness and brittleness of rock materials and their fragmentation as well as failure patterns in underground constructions. The FJM in PFC is more suitable for the numerical study of rock-like materials than finite element method, and it can obtain more coincident mechanical parameters and more microscopic failure characteristics.

\section{Data Availability}

All data used to support the findings of this study are available from the corresponding author upon request (list items: design drawings of the testing appartuas; the experimental test data; all the PFC codes).

\section{Conflicts of Interest}

The authors declare no conflicts of interest.

\section{Acknowledgments}

The research was supported by the National Key Research and Development Program of China (Grant no. 2016YFC0600904).

\section{References}

[1] T. Szwedzicki, "Indentation hardness testing of rock," International Journal of Rock Mechanics and Mining Sciences, vol. 35, no. 6, pp. 825-829, 1998.

[2] S. Yagiz, "Assessment of brittleness using rock strength and density with punch penetration test," Tunnelling and Underground Space Technology, vol. 24, no. 1, pp. 66-74, 2009.

[3] F. I. Shalabi, E. J. Cording, and O. H. Al-Hattamleh, "Estimation of rock engineering properties using hardness tests," Engineering Geology, vol. 90, no. 3-4, pp. 138-147, 2007.

[4] L. Xuefeng, W. Shibo, G. Shirong, R. Malekian, and L. Zhixiong, "Investigation on the influence mechanism of rock brittleness on rock fragmentation and cutting performance by discrete element method," Measurement, vol. 113, pp. 120-130, 2018.

[5] M. Fan, Y. Jin, M. Chen, and Z. Geng, "Mechanical characterization of shale through instrumented indentation test," Journal of Petroleum Science and Engineering, vol. 174, pp. 607-616, 2019.

[6] X. F. Li, H. B. Li, Y. Q. Liu, Q. C. Zhou, and X. Xia, "Numerical simulation of rock fragmentation mechanisms subject to 
wedge penetration for TBMs," Tunnelling and Underground Space Technology, vol. 53, pp. 96-108, 2016.

[7] X. F. Li, H. B. Li, L. W. Liu, Y. Q. Liu, M. H. Ju, and J. Zhao, "Investigating the crack initiation and propagation mechanism in brittle rocks using grain-based finite-discrete element method," International Journal of Rock Mechanics and Mining Sciences, vol. 127, Article ID 104219, 2020.

[8] S. Wang, X. Li, K. Du, and S. Wang, "Experimental investigation of hard rock fragmentation using a conical pick on true triaxial test apparatus," Tunnelling and Underground Space Technology, vol. 79, no. 1, pp. 210-223, 2018.

[9] L. H. Chen and J. F. Labuz, "Indentation of rock by wedgeshaped tools," International Journal of Rock Mechanics and Mining Sciences, vol. 43, no. 7, pp. 1023-1033, 2006.

[10] L. J. Yin, Q. M. Gong, H. S. Ma, J. Zhao, and X. B. Zhao, "Use of indentation tests to study the influence of confining stress on rock fragmentation by a TBM cutter," International Journal of Rock Mechanics and Mining Sciences, vol. 72, pp. 261-276, 2014.

[11] N. G. Yilmaz, D. Tumac, and R. M. Goktan, "Rock cuttability assessment using the concept of hybrid dynamic hardness $(\mathrm{HDH}), "$ Bulletin of Engineering Geology and the Environment, vol. 74, no. 4, pp. 1363-1374, 2015.

[12] P. Q. Ji, X. P. Zhang, and Q. Zhang, "Partide flow code analysis of effect of ductility-brittleness change on TBM cutters rock fragmentation process and its failure mode," Yantu Lixue/ Rock and Soil Mechanics, vol. 37, no. S2, pp. 724-734, 2016.

[13] C. Balci, M. A. Demircin, H. Copur, and H. Tuncdemir, "Estimation of optimum specific energy based on rock properties for assessment of roadheader performance," SIAMM-Journal of the Southern African Institute of Mining and Metallurgy, vol. 104, no. 11, pp. 633-642, 2004.

[14] S. P. Singh, "Criterion for the assessment of the cuttability of coal," in Advances In Mining Science And Technology, pp. 225-239, Elsevier, Amsterdam, Netherlands, 1987.

[15] G. E. Andreev, Brittle Failure of Rock Materials, CRC Press, Boca Raton, FL, USA, 1995.

[16] Q. Liu, "Evaluation of rock brittleness indexes on rock fragmentation efficiency by disc cutter," Yanshilixue Yu Gongcheng Xuebao/Chinese Journal of Rock Mechanics and Engineering, vol. 35, no. 3, pp. 498-510, 2016.

[17] R. Altindag, "Correlation of specific energy with rock brittleness concepts on rock cutting," Journal of the Southern African Institute of Mining and Metallurgy, vol. 103, no. 3, pp. 163-171, 2003.

[18] X.-X. Yang and W.-G. Qiao, "Numerical investigation of the shear behavior of granite materials containing discontinuous joints by utilizing the flat-joint model," Computers and Geotechnics, vol. 104, pp. 69-80, 2018.

[19] M. Chen, S. Yang, R. P. Gamage et al., "Fracture processes of rock-like specimens containing nonpersistent fissures under uniaxial compression,” Energies, vol. 12, no. 1, p. 79, 2019.

[20] L. N. Y. Wong and H. H. Einstein, "Crack coalescence in molded gypsum and carrara marble: part 1. Macroscopic observations and interpretation," Rock Mechanics and Rock Engineering, vol. 42, no. 3, pp. 475-511, 2009.

[21] X. Li, S. Wang, R. Malekian, S. Hao, and Z. Li, "Numerical simulation of rock breakage modes under confining pressures in deep mining: an experimental investigation," IEEE Access, vol. 4, pp. 5710-5720, 2016.

[22] L. J. Yin, Q. M. Gong, and J. Zhao, "Study on rock mass boreability by TBM penetration test under different in situ stress conditions," Tunnelling and Underground Space Technology, vol. 43, pp. 413-425, 2014.
[23] H. Alehossein, E. Detournay, and H. Huang, "An analytical model for the indentation of rocks by blunt tools," Rock Mechanics and Rock Engineering, vol. 33, no. 4, pp. 267-284, 2000.

[24] D. O. Potyondy, "PFC2D Flat-Joint Contact Model," in Technical Memorandum ICG7138-L, Itasca Consulting Group, Inc., Minneapolis, MN, USA, 2012.

[25] Itasca Consulting Group Inc, PFC Manual for Version 5.0, Itasca Consulting Group Inc., Minneapolis, MN, USA, 2018.

[26] S. Wu and X. Xu, "A study of three intrinsic problems of the classic discrete element method using flat-joint model," Rock Mechanics and Rock Engineering, vol. 49, no. 5, pp. 1813-1830, 2016.

[27] X. Ding and L. Zhang, "A new contact model to improve the simulated ratio of unconfined compressive strength to tensile strength in bonded particle models," International Journal of Rock Mechanics and Mining Sciences, vol. 69, pp. 111-119, 2014. 